Rev. Fac. Med. vet. Zootec. Univ. S. Paulo

$12: 149-62,1975$

\title{
PESO E RENDIMENTO DA CARCAÇA EM DUAS LINHAGENS DE AVES PARA CORTE
}

\author{
Cassio Xavier de MENDONÇA JUNIOR * \\ Fernando ANDREASI * \\ Flavio PRADA ** \\ João Silva Marcondes VEIGA ** \\ Sonia Maria Andreasi MENDONÇA ***
}

RFMV-A/14

Mendonça Junior, C. X. de; Andrgasi, F.; Prada, F.; Veiga, J. S. M.; MendoncA, S. M. A. - Peso e rendimento da carcaça em duas linhagens de aves para corte. Rev. Fac. Med. vet. Zootec. Univ. S. Paulo, $12: 149-62,1975$.

RESUMo: Com a finalidade de se estimar o peso e o rendimento da carcaça, de uma populaçāo de 809 aves abatidas, especializadas para produçāo de carne, foram sorteados 111 machos e 111 fêmeas da linhagem denominada " $A$ " e igual número de exemplares da linhagem " $B$ ", perfazendo um total de 444 aves. $A$ matança foi realizada em moldes industriais com jejum prévio de 14 horas.

Os niveis percentuais de rendimento da carcaça foram significantemente mais elevados na linhagem $B$, embora carcaças mais pesadas tenham sido obtidas na linhagem $A$.

Apesar dos machos terem proporcionado carcaças mais pesadas, não foram consignadas, entre sexos, diferenças significantes no que tange ao rendimento.

Por outro lado, o peso vivo mostrou-se estreitamente relacionado com o peso da carcaça, sendo os valores de " $r$ " todos superiores a 0,900 .

Os coeficientes de determinação e equações de regressão foram também determinados.

Dados relativos ao peso do coração, fígado, moela, cabeça e pescoço e pés foram obtidos e relacionados ao peso vivo médio das aves.

UNITERmos: Frangos*; Carcaça*; Visceras*; Linhagens.

\section{N T R O D U C $\AA$ O}

A avicultura no Brasil vem sofrendo sensivel desenvolvimento graças, principalmente, à iniciativa privada que tem envidado ingentes esforços no sentido de, res- saltando a excelência do valor nutritivo do ovo e da carne de frango, atingir o objetivo precipuo de elevar o nível qualitativo e quantitativo da dieta alimentar da população.

- Professor-Adjunto.

* Professor Assistente Doutor.

Departamento de Produção Animal da Faculdade de Medicina Veterinária e Zootecnia da U.S.P.

** Médico-Veterinário. 
MENDONCA JUNIOR, C. X. de; ANDREASI, F.; PRADA, F.; VEIGA, J. S. M.; MENDONCA, S. M. A. - Peso e rendimento da carcaça em duas linhagens de aves para corte. Rev. Fac. Med. vet. Zootec. Univ. S. Paulo, 12:149-62, 1975.

Entretanto, reduzido número de trabalhos relativos ao peso da carcaça e seu rendimento, tendo em mira focalizar o problema em termos industriais, tem sido realizado em nosso meio.

A presente investigação tem por finalidade o estudo do peso e rendimento de carcaça oriunda de duas linhagens de aves para corte, bem como das vísceras comestíveis e outras partes de qualidade inferior tais como pés, cabeça e pescoço.

\section{I T E R A T U R A}

Estudos empreendidos por MCNALLY \& SPICKNALL ${ }^{16,17}$ em Rhode Island Red, mostraram existir correlação linear do peso vivo, não só em relação ao peso da carcaça eviscerada, como ainda ao peso da carne comestível. REYNTENS et al. ${ }^{23}$, em várias raças e cruzamentos, também en contraram esta dependência de significado estatístico entre peso vivo e peso da carcaça.

JAAP et al. ${ }^{14}$, em 1.824 frangos de corte de 44 linhagens e cruzamentos, anotaram as 12 semanas de idade, que a aceleração do ritmo de crescimento era acompanhada pelo maior rendimento da carcaça eviscerada, havendo portanto uma relação linear entre estas características. No mesmo sentido, RANGANATHAN et al ${ }^{22}$ e SARAZA et et al. ${ }^{25}$, observaram rendimento mais elevado em frangos de maior peso.

SWANSON et al. ${ }^{29}$, em extensa revisão bibliográfica, destacaram os principals fatores que influenciariam o grau de rendimento no abate, entre os quais são citados, a constituição genética da ave, tipo de alimentação, período de jejum, métodos de sangria e evisceração e, por último, a refrigeração da carcaça. Neste partícular, alguns prognosticaram que o período de jejum de 24 horas ${ }^{18}$ ou por tempo superior ${ }^{26}$, ocasionariam menor rendimento da carcaça eviscerada.

Quanto à constituição genética, parece existir acordo de que os frangos híbridos apresentam rendimentos superiores $2,9,10,12$, 23,28 , embora variações entre raças possam ocorrer $2,22,23,25$. O Cornish, por exemplo, rende consistentemente mais, em termos de carne comestível que outras raças e cruzamentos $13,20,29$. Por outro lado, vários autores $7,8,9,10,23$ têm registrado di- ferentes índices de rendimento entre inúmeros cruzamentos efetuados.

Parece ainda que o critério adotado nos esquemas de acasalamentos pode influenciar o rendimento. De fato, utilizando-se o Cornish macho, foi obtido um maior rendimento de carne comestivel, principalmente da região do peito, em cotejo a outros esquemas de cruzamentos e acasalamentos dentro de raças puras ${ }^{28}$.

No atinente ao sexo, alguns autores, $6,8,13,19,20$ verificaram maior rendimento percentual nos machos, enquanto outros $7,9,10,21,30$, registraram valores mais elevados para as fêmeas.

De acordo com a fase de desenvolvimento e para fins de apuração e classificação de rendimento, RANGANATHAN et $a .^{22}$, ao mencionarem dados da FAO, citaram rendimentos de $64 \%$ do peso vivo no caso de "broilers" e "fryers", 65\% em "roasters" e $68 \%$ em galinhas. Todavia, LOWE \& VERNON 15 encontraram em "broilers" $62,9 \%$, em "fryers" $67,8 \%$ e em "roasters" 70,6\% de rendimento da carcaça. Já BROWN \& BEAN ${ }^{5}$ anotaram 72,4\% em "broilers", $73,9 \%$ em "fryers", 74,6\% em "roasters", 67,2\% em galinhas leves e $69,4 \%$ em galinhas pesadas, o que resultou a média de $71,5 \%$, englobando as 5 classes estudadas. Por seu turno, SANS EGANA ${ }^{24}$ registrou ser o rendimento da carcaça, da ordem de $62 \%$ para franguinhos, $67 \%$ para galinhas e $65 \%$ para frangos.

Como se depreende, os valores de rendimento oscilam pronunciadamente visto que os pesquisadores, na maioria das vezes, não forneceram maiores detalhes quanto às condições sob as quais se desenrolaram seus experimentos, isto é, se em moldes restritos ou em nível industrial ${ }^{29}$.

Alguns autores $1,5,14,16,17,20,22$ $23,26,30$ incluíram ao peso da carcaça, as vísceras comestíveis, determinando com isso, índices de rendimento mais elevados em relação ao peso vivo $-66,4$ a $80,6 \%$ - se comparados aos obtidos - 52,3 a $73,7 \%$ com exclusão das vísceras $1,2,3,6$, $11,12,13,15,16,17,19,24$ :

No Brasil RAIMO 21 em 10 fêmeas e 10 machos de aves cruzadas - Cornish-cross - cujos pesos médios eram de 1.524 a 1.558 gramas, respectivamente, encontrou em carcaça eviscerada sem cabeça, pescoço e pés, peso da ordem de 985 gramas para 
MENDONÇA JUNIOR, C. $X$. de; ANDREASI, F.; PRADA, F.; VEIGA, J. S. M.; MENDONÇA, S. M. A. - Peso e rendimento da carcaça em duas linhagens de aves para corte. Rev. Fac. Med. vet. Zootec. Univ. S. Paulo, $12: 149-62,1975$.

as fêmeas e 933 gramas para os machos, com rendimentos percentuais de $64,6 \%$ e $59,2 \%$, respectivamente.

Ainda entre nós, CAMPOS \& CHQUILOFF' 6 em aves especializadas para corte, abatidas aos 70 dias de idade, verificaram rendimentos de $64,10 \%$ e $63,62 \%$, respectivamente, para machos e fêmeas.

\section{MATERIAL e MÉTODOS}

\section{1 - Abate}

Como material de estudo para a presente pesquisa foram empregadas aves de duas linhagens, denominadas de A e B.

De uma populaçāo de 809 aves abatidas, foram separadas, ao acaso, 111 unidades de cada sexo e dentro da mesma linhagem, perfazendo um total de 444 amostras.

As aves ficaram em jejum de alimento durante 14 horas, procedendo-se em seguida ao sacrifício sem insensibilização. Para tanto, as aves foram colocadas em funis, de cabeça para baixo, seguindo-se o seccionamento das carótidas e jugulares na altura da base do véu palatino.

Após a sangria, as aves foram escaldadas em tanque apropriado contendo água cuja temperatura oscilava entre 55 a $60^{\circ} \mathrm{C}$.

Imediatamente após a operação de escaldamento, as aves foram submetidas à depenação, efetuada segundo processo totalmente mecanizado, para em seguida, ganharem o setor de evisceração, no qual procedeu-se a retirada das vísceras torácicas e abdominais pelo corte convencional de matadouro, ou seja, pela incisão circulação ao redor da cloaca e tração das vísceras.

Finalmente, completou-se o preparo das carcaças pelo corte do pescoco na altura aproximada da $10^{a}$ vértebra cervical e corte dos pés ao nível da articulação tiblo-metatarsiana.

A carcaça ainda quente, obtida nas condições acima, foi finalmente pesada. Devemos entender como peso real da mesma, e peso vivo menos a soma dos pesos correspondentes às penas, ao sangue escoado, às vísceras, aos pés, à cabeça e ao pescoço.

Das 809 aves abatidas, foram colhidas, ao acaso, 102 amostras, de coraçāo, fígado, moela, conjunto cabeça e pescoco e pés, as quais foram pesadas em balança com sensibilidade de $1 \mathrm{~g}$.

\section{2 - Interpretação estatística}

Para interpretação estatística dos resultados foi utilizada análise de variância, modelo fixo, segundo preceitua SNEDECOR \& COCHRAN 27. Para os dados expressos em porcentagem foi utilizada transformação arco seno 27 e a homogeneidade das variâncias inferida pelo teste de Cochran 4 .

Foi previamente estitulado o nível de significância de $5 \%$ para a interpretação estatística dos resultados.

\section{R E S U L T A D O S}

Na tabela 1 estão registrados os pesos médios das aves e das carcaças, bem como os rendimentos das mesmas, consoante a distribuição em linhagens e sexos.

A simples inspeção da tabela 1, verifica-se que a linhagem "A" apresentou maiores pesos da carcaca, quando posta em confronto com a linhagem "B". As diferenças apuradas entre linhagens foram julgadas significativas pela análise de variância (tabela 2 ).

No que se refere ao rendimento percentual da carcaca, a linhagem " $B$ " apresentou valor médio superior - 68,2\% - ao assinalado na linhagem "A" - 67,1\% (tabela 1), diferença esta tida como significante (tabela 3 ).

Com relação ao sexo, foi verificada diferenca significativa, uma vez que os machos proporcionaram pesos da carcaça, superiores aos assinalados para as fêmeas (tabela 2).

No que tange aos coeficientes de variação, a linhagem "A" mostrou menor variabilidade no peso da carcaca que a linhagem "B", à semelhança do que ocorreu em relação ao peso por ocasião do abate, ou seja, do peso vivo (tabela 1 ).

Quanto às relaçōes entre peso vivo e peso da carcaça em cada linhagem e sexo, foram encontradas associações estreitas traduzidas pelos coeficientes de correlação significativos cuja amplitude situou-se entre 0,900 para os machos da linhagem 
MENDONCA JUNIOR, C. $X$. de; ANDREASI, F.; PRADA, F.; VEIGA, J. S. M.; MENDONCA, S. M. A. - Peso e rendimento da carcaça em duas linhagens de aves para corte. Rev. Fac. Med. vet. Zootec. Univ. S. Paulo, $12: 149-62,1975$.

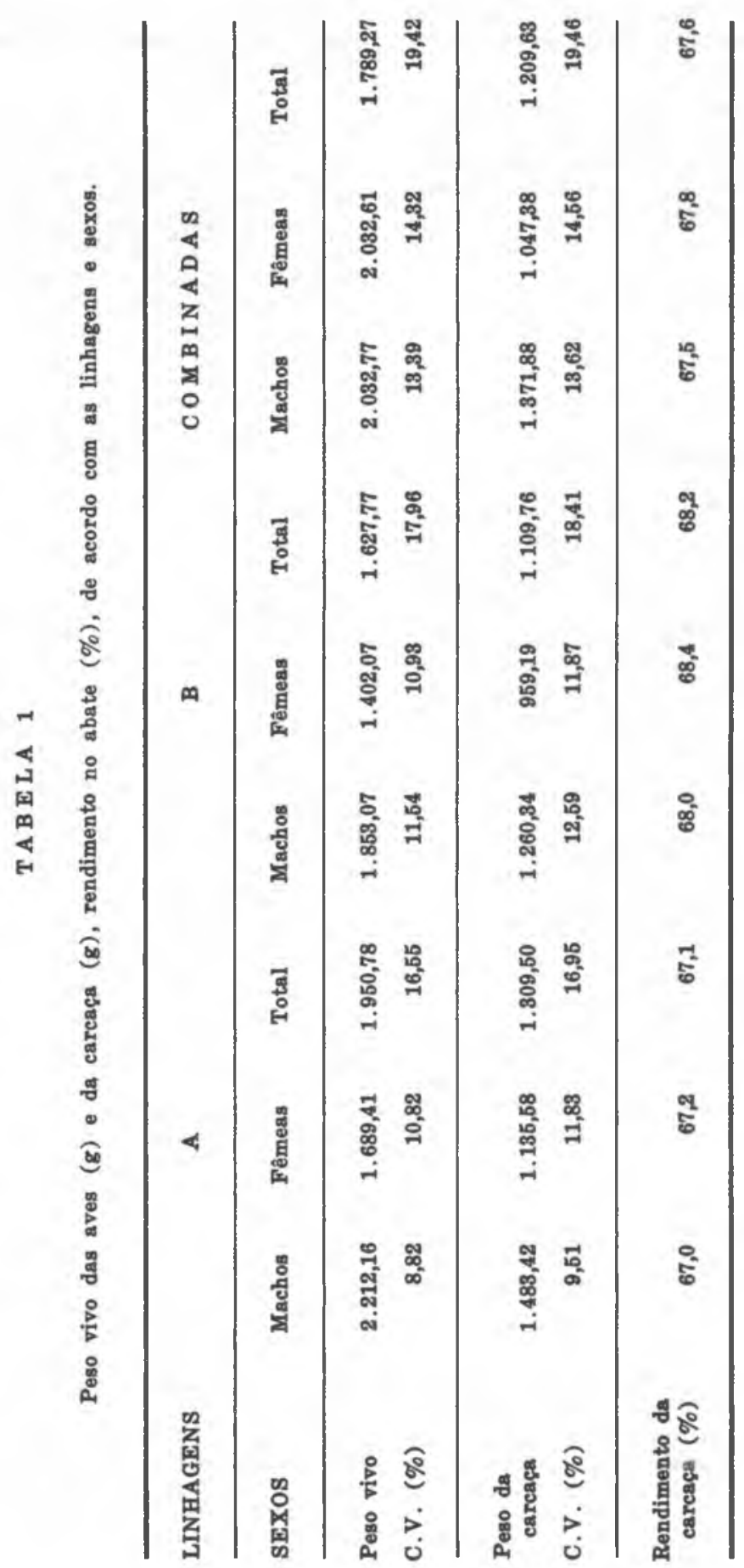


MENDONCA JUNIOR, C. X. de; ANDREASI, F.; PRADA, F.; VEIGA, J. S. M.; MENDONCA S. M. A. - Peso e rendimento da carcaça em duas linhagens de aves para corte. Rev. Fac. Med. vet. Zootec. Univ. S. Paulo, 12:149-62, 1975.

T A B E L A 2

Análise de variância do peso da carcaça, referente às linhagens e sexos.

\begin{tabular}{lrrrr}
\hline FONTES DE VARIACAO & G.L. & \multicolumn{1}{c}{ S.Q. } & Q.M. & F. \\
\hline \hline Linhagens (L) & 1 & $4.428 .407,58$ & $4.428 .407,58$ & $232,82 *$ \\
Sexos (S) & 1 & $11.688 .003,25$ & $11.688 .003,25$ & $614,49 *$ \\
L X S & 1 & $60.480,01$ & $60.480,01$ & 3,18 \\
Resíduo & 440 & $8.369 .014,05$ & $19.020,49$ & - \\
TOTAL & 443 & $24.545 .904,89$ & - & - \\
\end{tabular}

* $\mathbf{P} \leq 0,05$

T A B E L A 3

Análise de variância do rendimento da carcaça, concernente às linhagens e sexos.

\begin{tabular}{lrrrr}
\hline FONTES DE VARIAÇO & G.L. & S.Q. & Q.M. & F. \\
\hline \hline Linhagens (L) & 1 & 46,08 & 46,08 & $13,51 *$ \\
Sexos (S) & 1 & 3,31 & 3,31 & 0,97 \\
L x S & 1 & 0,80 & 0,80 & 0,23 \\
Residuo & 440 & $1.502,08$ & 3,41 & - \\
TOTAL & 443 & $1.652,27$ & - & - \\
\hline
\end{tabular}

- $\mathbf{P} \leq 0,05$ 
MENDONÇA JUNIOR, C. X. de; ANDREASI, F.; PRADA, F.; VEIGA, J. S. M.; MENDONÇA,

S. M. A. - Peso e rendimento da carcaça em duas linhagens de aves para corte. Rev. Fac. Med. vet. Zootec. Univ. S. Paulo, 12:149-62, 1975.

"A" e 0,974 atribuído às linhagens " $\mathrm{A}$ " $\mathrm{e}$ "B" combinadas (tabela 4). As linhas de regressão do peso da carcaça em função do peso vivo, bem como as equaçōes de regressão e coeficientes de determinação, podem ser vistos nas figuras $1,2,3$ e 4 .

Na tabela 5, são apresentados os pesos médios de amostras de coração, fígado, moela, cabeça e pescoço e pés, sem descriminação de linhagem e sexo, as quais foram retiradas, ao acaso, por ocasião do abate. A amplitude de variação do peso vivo da população da qual provieram as 102 amostras, variou de 1.020 a $2.660 \mathrm{~g}$ com valor médio de $1.766 \mathrm{~g}$.
T A B E L A 4

Correlação entre peso vivo e peso da carcaça de acordo com as linhagens e sexos.

\begin{tabular}{|c|c|c|c|}
\hline Linh & $\mathbf{A}$ & B & $\begin{array}{c}\text { Combinadas } \\
(\mathbf{A}+\mathbf{B})\end{array}$ \\
\hline Machos & 0,900 * & 0,947 & $0,952 *$ \\
\hline Fêmeas & 0,918 & 0,927 & 0,947 \\
\hline TOTAL & 0,966 & 0,973 & 0,974 \\
\hline
\end{tabular}

T A B E L 5

Peso médio de vísceras comestiveis e outras partes da ave - 102 amostras - sem discriminação de linhagem e sexo.

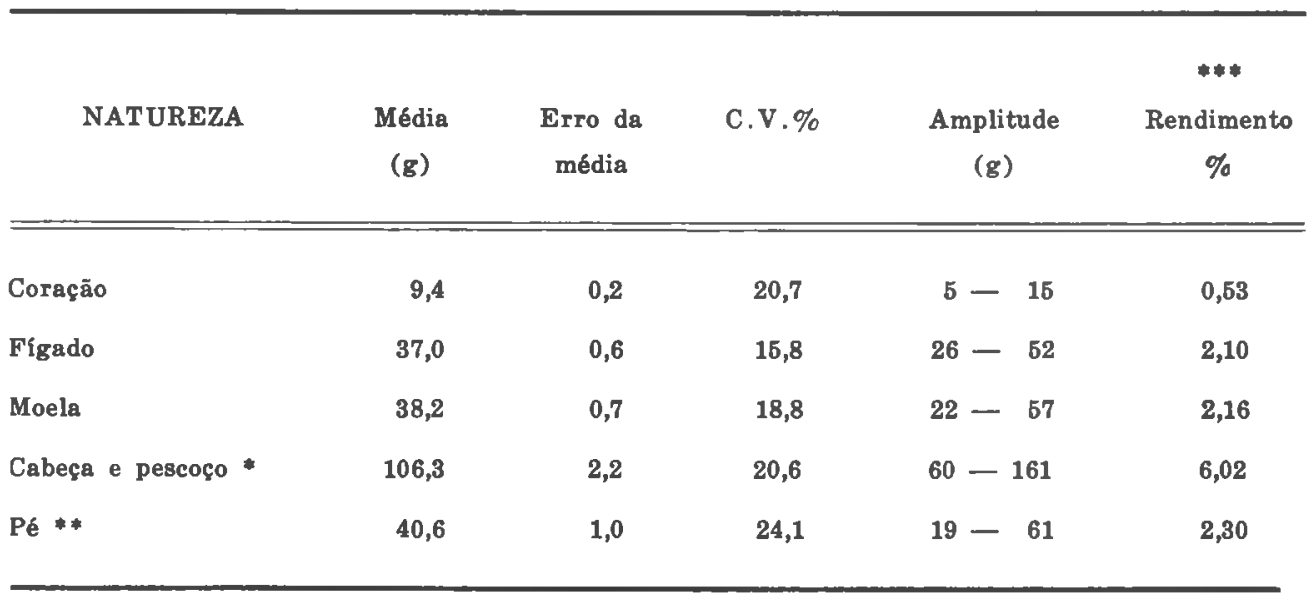

* sem bico e o pescoço seccionado na altura da $10 .^{\text {a }}$ vértebra cervical.

* Refere-se a um pé, sem unhas e pele dos dedos.

** Em relação ao peso vivo médio das aves $(1.766 \mathrm{~g})$. 
MENDONCA JUNIOR, C. X. de; ANDREASI, F.; PRADA, F.; VEIGA, J. S. M.; MENDONCA, S. M. A. - Peso e rendimento da carcaça em duas linhagens de aves para corte. Rev. Fac. Med. vet. Zootec. Univ. S. Paulo, 12:149-62, 1975.

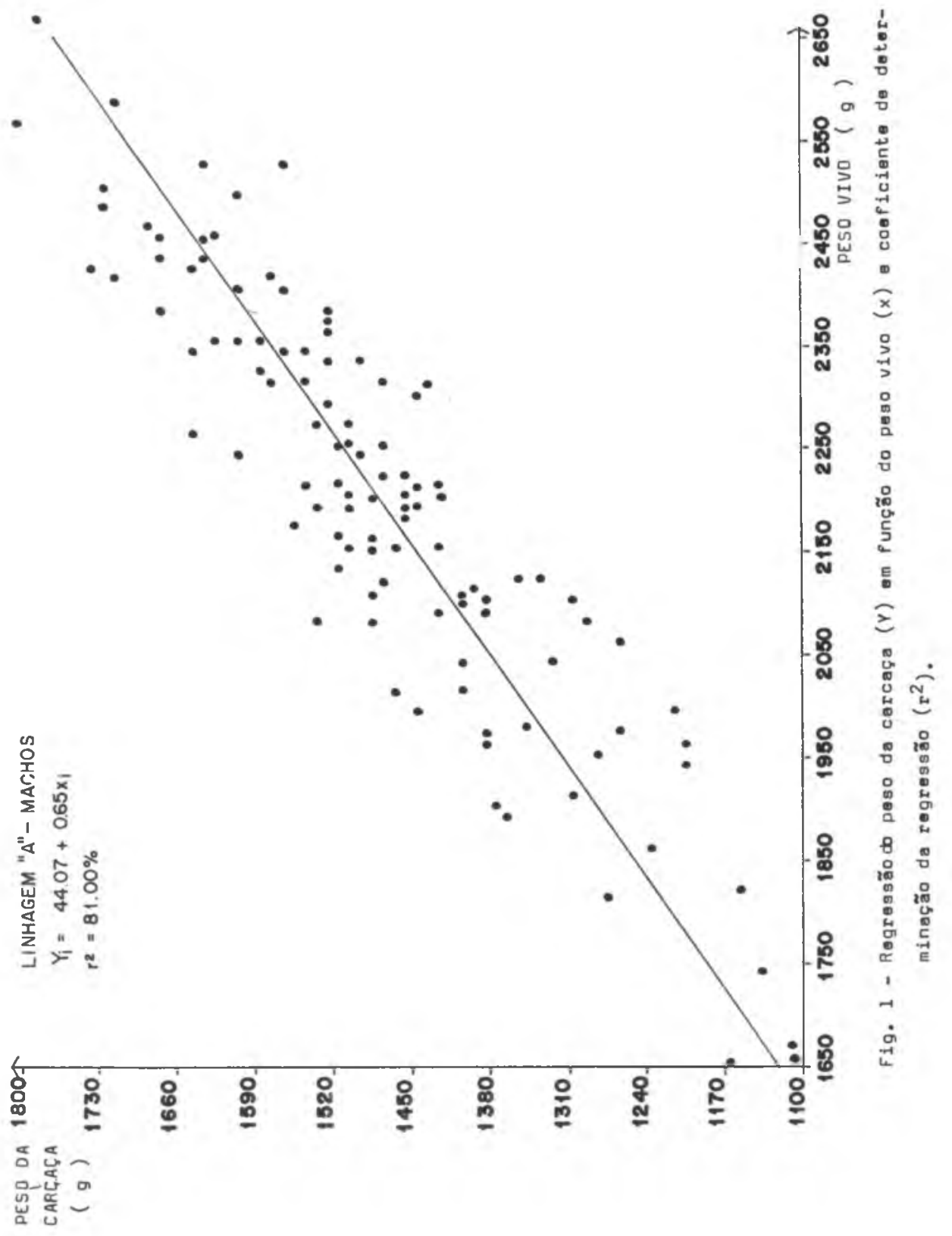


MENDONCA JUNIOR, C. $X$. de; ANDREASI, F.; PRADA, F.; VEIGA, J. S. M.; MENDONCA S. M. A. - Peso e rendimento da carcaça em duas linhagens de aves para corte. Rev. Fac. Med. vet. Zootec. Univ. S. Paulo, 12:149-62, 1975.

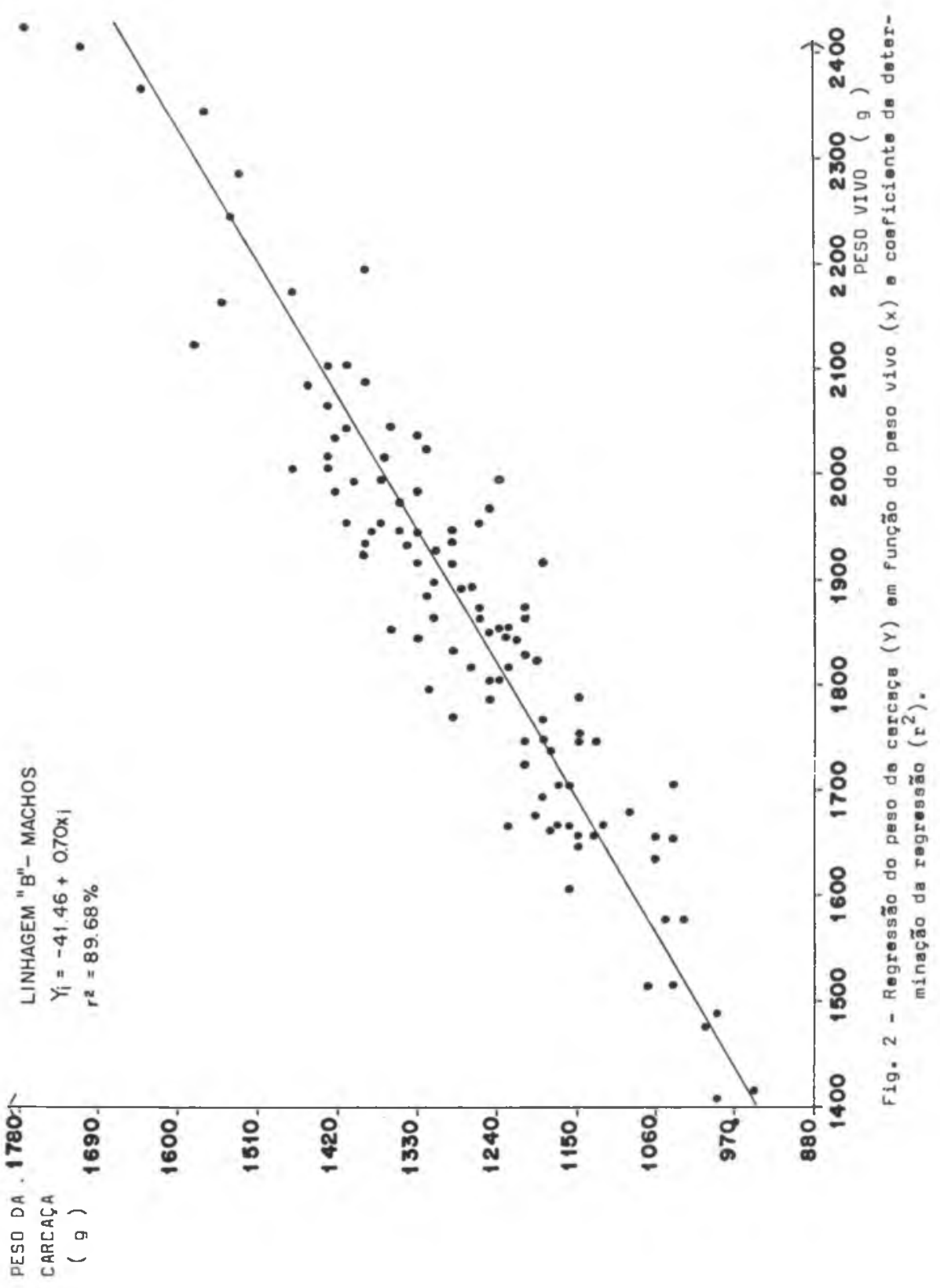


MENDONCA JUNIOR, C. X. de; ANDREASI, F.; PRADA, F.; VEIGA, J. S. M.; MENDONCA, S. M. A. - Peso e rendimento da carcaça em duas linhagens de aves para corte. Rev. Fac. Med. vet. Zootec. Univ. S. Paulo, 12:149-62, 1975.

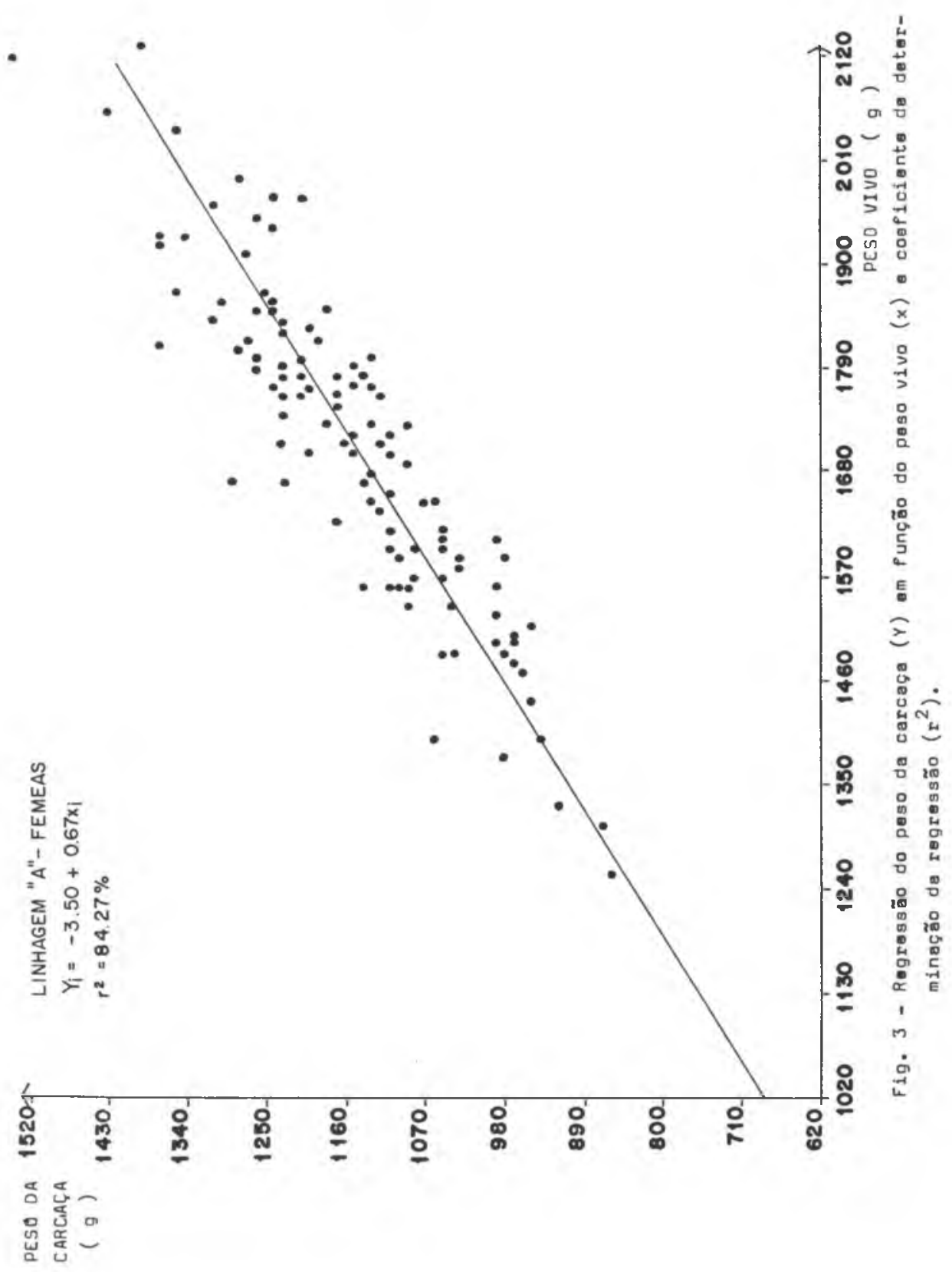


MENDONCA JUNIOR, C. X. de; ANDREASI, F.; PRADA, F.; VEIGA, J. \&, M.; MENDONCA

S. M. A. - Peso e rendimento da carcaça em duas linhagens de aves para corte. Rev.

Fac. Med. vet. Zootec. Univ. S. Paulo, 12:149-62, 1975.

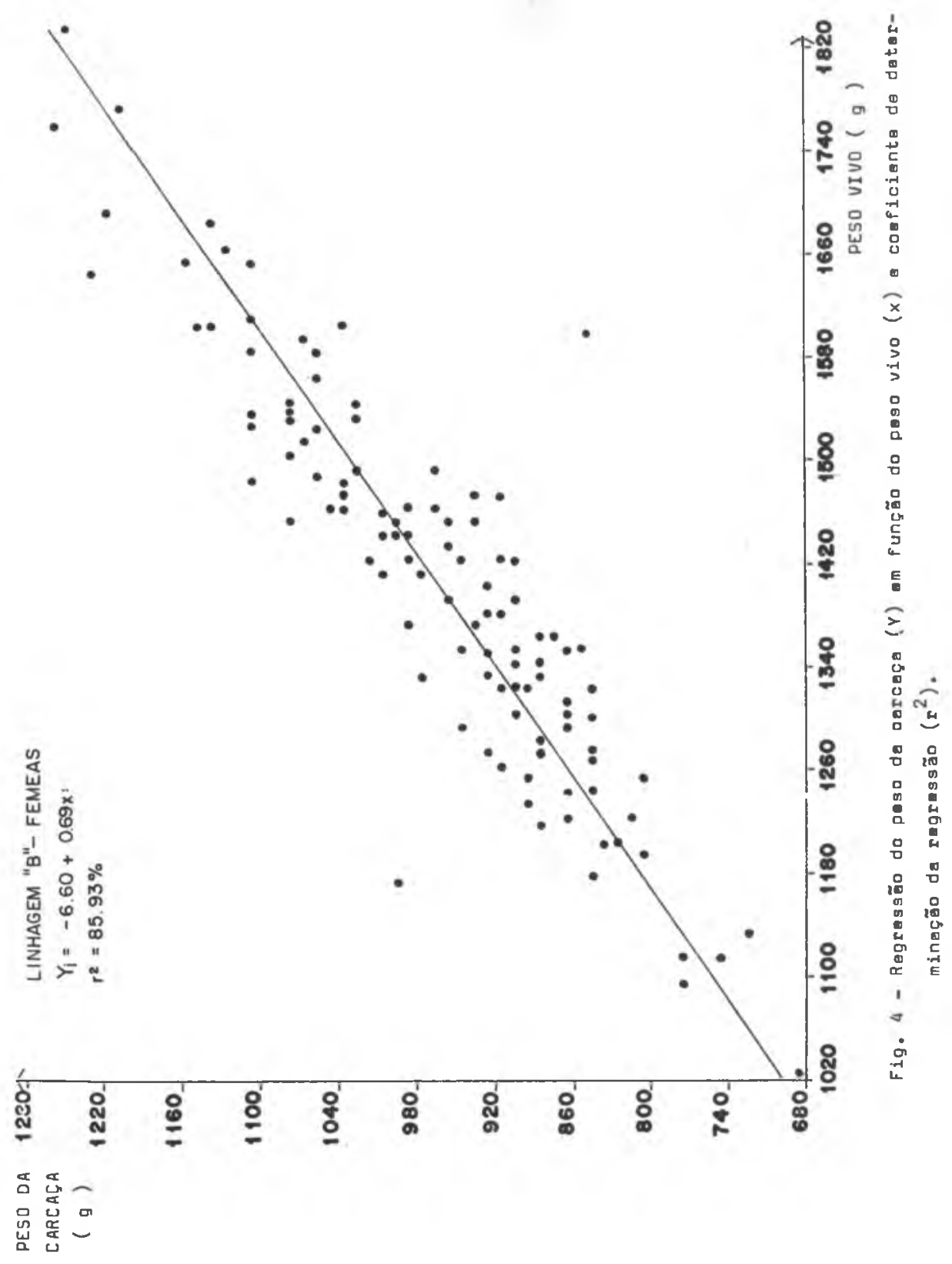


MENDONÇA JUNIOR, C. X. de; ANDREASI, F.; PRADA, F.; VEIGA, J. S. M.; MENDONÇA, S. M. A. - Peso e rendimento da carcaça em duas linhagens de aves para corte. Rev. Fac. Med. vet. Zootec. Univ. S. Paulo, $12: 149-62,1975$.

\section{I S C U S S $\mathrm{O}$}

\section{1 - Peso da carcaça}

Os resultados auferidos na linhagem " $A$ " superaram os assinalados por APARICIO MACARRO $^{3} \mathrm{em}$ ambas as linhagens por ele estudadas, ou seja de $1.166,11 \mathrm{~g}$ para a linhagem Kok e de. $1.205,65 \mathrm{~g}$ para a Nichols.

Em relação ao sexo, os machos deram sempre origem a carcaças mais pesadas que as fêmeas (tabela 1).

Quanto à variabilidade, as carcaças das aves da ilnhagem " $A$ " foram ligeiramente mais uniformes - $16,95 \%$ - que as da linhagem " $B$ " - 18,41\% — valores estes, por sua vez, mais elevados se comparados aos verificados por APARICIO MACAR$\mathrm{RO}^{3}$ que, em linhagens Kok e Nichols, obtiveram $13,57 \%$ e $6,71 \%$, respectivamente. Por seu lado, REYNTENS et al..$^{23} \mathrm{em}$ várias raças e produtos de cruzamentos, encontraram coeficientes de variação entre 8,0 e $17,4 \%$.

\section{2 - Rendimento da carcaça}

Se examinarmos a tabela 1 , verificaremos que as aves da linhagem " $B$ ", apresentaram malor rendimento ao abate $68,2 \%$ - que o verificado - $67,1 \%$ - na linhagem " $A$ ". Tal diferença foi julgada significante (tabela 3 ). Face às discrepârıcias de rendimentos surpreendidas entre as diversas raças e produtos de cruzamentos, já ressaltadas por vários autores $2,3,7$, $8,9,10,12,13,14,19,20,22,23,25,28$, a diferença entre as linhagens " $A$ " a " $B$ ", não parece merecer senão alguns comentários.

De fato, os rendimentos percentuais apurados em ambas as linhagens se equivaleram aos consignados - 67,6 a $68,5 \%$ - por MORAN \& ORR ${ }^{19}$ em frangos de corte abatidos com 58 dias de idade e, aos de MAY \& BRUNSON ${ }^{18}$ que obtiveram rendimentos variando de 68,5 a $70,1 \%$. No entanto, foram ligeiramente mais elevados que os apurados por APARICIO MACAR$\mathrm{RO}^{3}$ em linhagem Kok - 66,60\% - e Nichols - 64,91\% -; por APARICIO MACARRO $^{2}$ em aves de diferentes procedências; por CAMPOS \& CHQUILOFF ${ }^{6}$ que, em aves especializadas para produção de carne, encontraram $63,65 \% \mathrm{e}$, por outros autores $1,3,6,15,24$ para a categoria de "broilers" cujos valores oscilaram entre 61,1 e $66,8 \%$. Contudo, foram inferiores aos aufeirdos por GYLES et al. ${ }^{12}$ em aves de 11 semanas, provindas de vários cruzamentos; aos de AFIFI \& RASHEED ${ }^{1}$, em duas raças especializadas para corte e aos de vários autores citados por SWANSON et al $^{29}$. Outros pesquisadores $5,14,22,23,26,30$ que incluíram vísceras comestíveis nas carcaças evisceradas, obtiveram dados mais elevados.

Os rendimentos auferidos nos machos $67,0 \%$ para a lihagem " $A$ " e $68,0 \%$ para a linhagem " $B$ " - com valor médio de $67,5 \%$, bem como os referidos para as fêmeas - $67,2 \%$ para a linhagem " $A$ " $\mathrm{e}$ $68,4 \%$ para a " $\mathrm{B}$ " - foram muito próximos, sendo assim a diferença entre sexos julgada não significante (tabela 3 ).

Alguns autores 6, 8, 13,19,20 têm verificado rendimentos das carcacas mais elevados para os machos enquanto outros $7,9,10,30$ favorecendo as fêmeas, resultando na maioria das observações, discrepâncias da ordem de 1 a $2 \%$, o que confirma as nossas asserções.

Em razão de ter incluído no peso da carcaça as vísceras comestíveis, SMIDT et al. $^{26}$ assinalaram em machos de alta linhagem abatidos com 76 dias de idade, rendimento da ordem de $75,5 \%$, bem superior aos consignados - $67 \%$ e $68,0-$, em machos do presente estudo.

A falta de informaçōes mais detalhadas na mairia dos trabalhos compulsados na literatura, dificultou sobremaneira a comparação de dados desta natureza.

$$
\begin{aligned}
& 3 \text { - Correlação e regressāo do peso vivo } \\
& \text { e peso da carcaça }
\end{aligned}
$$

Se atentarmos para a tabela 4 , a estreita ligação encontrada entre peso vivo e peso da carcaça, com valores de " $r$ " superiores a 0,900 corrobora os achados de vários autores ${ }^{16,17,23 .}$

Pela apreciação das figuras 1 e 2 podemos verificar através dos coeficientes de determinação - $\mathrm{r}^{2}-$ que, nos machos, 
MENDONÇA JUNIOR, C. X. de; ANDREASI, F.; PRADA, F.; VEIGA, J. S. M.; MENDONÇA, S. M. A. - Peso e rendimento da carcaça em duas linhagens de aves para corte. Rev. Fac. Med. vet. Zootec. Univ. S. Paulo, $12: 149-62,1975$.

- peso vivo seria responsável por $81,00 \%$ e $89,68 \%$ da variação encontrada no peso da carcaça, respectivamente, para as linhagens "A" $\mathrm{e}$ " $B$ ".

Por outro lado, os valores de " $r$ " correspondentes às fêmeas, foram muito próximos aos auferidos para os machos, ou seja, de $84,27 \%$ para a linhagem " $A$ " e $85,93 \%$ para a linhagem " $B$ " (figuras 3 e 4).

MCNALLY \& SPICKNALL ${ }^{17}$ obtiveram em várias categorias de aves da raça Rhode Island Red, equação de regressão de $Y_{i}=-102,78+0,7051 x_{i}$, entre peso vivo $(x)$ e peso da carcaca $(Y)$ enquanto que no presente estudo as equaçōes foram de $Y_{i}=44,07+0,65 x_{i}$ para os machos da linhagem " $A$ " (figura 1) e de $Y_{i}=$ $-41,46+0,70 x_{i}$ para aqueles da linhagem "B" (figura 2). Para as fêmeas, as equaçōes encontradas foram de $Y_{i}=-3,50+$ $0,67 x_{i}$ na linhagem " $A$ " e de $Y_{i}=-6,60$ $+0,69 x_{1}$ para as linhagem " $B$ " (figuras 3 e 4 ).

\section{4 - Peso de visceras comestiveis e de ou- tras partes das aves}

Os pesos das vísceras comestiveis, auferidos no presente estudo (tabela 5) se aproximam aos de CAMPOS \& CHQUILOFF6 que assinalaram em 60 aves 30 machos e 30 fêmeas - pesando entre 960 e $2150 \mathrm{~g}$, amplitude de variação de 5-10 $\mathrm{g}$, 20-40 g e 30-50 g, para o coração, fígado e moela, respectivamente, com valores médios de $9,15 \mathrm{~g}, 31,65 \mathrm{~g}$ e $39,65 \mathrm{~g}$.

Os mesmos autores 6 assinalaram para um pé, intervalo de 25-55 g e média de $35,75 \mathrm{~g}$, muito próximos aos nossos resultados, e para a cabeça e pescoço, valor médio de $81 \mathrm{~g}$, inferior ao encontrado na presente investigação $(106,3 \mathrm{~g})$.
Os pesos assinalados por CAMPOS \& SHQUILOFF6, embora se apresentassem sistematicamente mais baixos, poderiam ser justificados pelo fato de, no presente estudo, as aves serem mais pesadas, ou seja, com peso médio de $1.776 \mathrm{~g}$, variando entre 1.020 e 2.660 gramas.

Por outro lado, o mesmo cotejo desta feita realizado em termos percentuais atinentes ao rendimento em relaça ao peso vivo médio das aves, os resultados passaram a se equivaler (tabela 5 ). De fato, os autores citados 6 encontraram $0,59 \%$, $2,06 \%, 2,58, \% \quad 5,26 \%$ e $2,32 \%$ de rendimento, respectivamente, para coração, fígado, moela, cabeça e pescoço e pé, muito próximos aos registrados no presente estudo (tabela 5)

Por outro lado, RAIMO ${ }^{21}$ encontrou para aves cruzadas, pesos médios de $132 \mathrm{~g}$ para cabeça e pescoço nos machos e $116 \mathrm{~g}$ para as fêmeas, valores estes mais elevados que os obtidos no presente estudo. No entanto, os pesos médios relativos a pé e coração se mostraram bem inferiores aos relatados na presente investigação.

\section{O N C L U S O E S}

1 - Os níveis percentuais relativos ao rendimento da carcaca foram mais elevados na linhagem "B", apesar de terem sido obtidas carcacas mais pesadas na linhagem "A".

2 - O rendimento da carcaça não sofreu influência devida ao sexo, muito embora os machos tivessem proporcionado carcaças, significantemente, mais pesadas.

3 - 0 peso vivo mostrou-se altamente correlacionado com o peso da carcaça. 
MENDONCA JUNIOR, C. X. de; ANDREASI, F.; PRADA, F.; VEIGA, J. S. M.; MENDONÇA, S. M. A. - Peso e rendimento da carcaca em duas linhagens de aves para corte. Rev. Fac. Med. vet. Zootec. Univ. S. Paulo, 12:149-62, 1975.

Mendonç Junior, C. X. de; Andreasi, F.; Prada, F.; Veiga, J. S. M.; MENDONCA, S. M. A. - Carcass yield in two strains of chicken for meat production. Rev. Fac. Med. ret. Zootec. Univ. S. Paulo, 12: $149-62,1975$.

SUMMARY: Were randomly selected, 809 chickens for meat production in order to compose two groups named here " $A$ " and " $B$ " strains.

After fastening for 14 hours, the birds were slaughtered in industrial condition.

Then, 111 males and 111 females were selected at random from each strain and their live weight, eviscerated carcass weight and yield of this late were recorded.

Based on live weight, the strain " $B$ " yielded higher percentage of eviscerated carcass than strain " $A$ ", although the heaviest carcass weights were obtained in strain " $A$ ".

Although heavier carcass weights were found in males, there no significant differences between sexes in relation to the carcass' yield.

Regression equations and coefficients of determination for the interrelation of live weight and carcass weight, were determined in relation to both sexes and strains.

Data from giblets - gizzard, heart and liver - and legs, heads and necks were also studied and discussed.

UNITERMS: Chicken*; Carcass*; Giblets*; Strains.

\section{REFERENCIAS BIBLIOGRAFICAS}

1. AFIFI, M. A. \& RASHEED, A. A. Slaughter and carcass studies 12-week old Fayoumi and Rhode Island Red birds. Poult. Sci., 45(4):801-5, 1966.

2. APARICIO MACARRO, J. B. - Determinacion del rendimiento a la canal en pollos explotados en bateria. Arch. Zootec., $6(22): 151-9,1957$.

3. APARICIO MACARRO, J. B. - Pollos híbridos, Kok y Nichols, en la producción de carne. Arch. Zootec., 13 (52) :323-46, 1964.

4. BOWKER, A. H. \& LIEBERMAN, G. J. Engineering statistics. Englewood Cliffs, N. J., Prentice-Hall, 1959, p. 198.

5. BROWN, P. B. \& BEAN, H. W. - The yield of edible meat from different market classes of chickens. Poult. Sci., $31(2): 232-4,1952$.
6. CAMPOS, E. J. \& CHQUILOFF, M. A. G. - Estudo sobre o rendimento de uma ave comercial especializada para produção de carne. Arq. Esc. 8usp. Vet. Est. Minas Gerais, 18:113-21, 1966.

7. DAVIDSON, J. A. et al. - Michigan broiler test n. ${ }^{\circ} 1$, summer 1955. $Q$ Bull. Mich. St. Univ. agric. Exp. Stn., $38(2): 210-5,1955$.

8. DAVIDSON, J. A. et al. - Michigan broiler test $\mathrm{n}^{\circ} 2$ fall 1955 . Q. Bull. Mich. St. Univ. agric. Exp. Stn., 38 (4) :486-92, 1956

9. DAVIDSON, J. A. et al. - Michigan broiler test $\mathrm{n} .^{\circ} \mathrm{5}$ winter 1957. Q. Bull. Mich. St. Univ. agric. Exp. Stn., 40 (1) :19-22, 1957 .

10. DAVIDSON, J. A. et al. - Michigan broiler test n. ${ }^{\circ} 6$ summer $1957 . Q$. Bull. Mich. St. Univ. agric. Exp. Stn. 40 (3) : 483-7, 1958. 
MENDONCA JUNIOR, C. X. de; ANDREASI, F.; PRADA, F.; VEIGA, J. S. M.; MENDONCA, S. M. A. - Peso e rendimento da carcaça em duas linhagens de aves para corte. Rev Fac. Med. vet. Zootec. Univ. S. Paulo, 12:149-62, 1975.

11. FONSECA, W. - Carne de ave. São Paulo, Obelisco, 1964.

12. GYLES, N. R. et al. - Carcass yield between breeding groups apud Poult. Sci., $33(5): 1057-8,1954$.

13. HATHAWAY, H. E. et al. - Meat yield of broilers of different breeds, strains and crosses. Poult. Sci., $32(6): 968-77$, 1953.

14. JAAP, R. G. et al. - Dressed and eviscerated meat yiels from chickens at twelve weeks of age. Poult. Sci., 29 (6) : 874-80, 1950 .

15. LOWE, B. \& VERNON, W. M. - Poultry for the table as influenced by market class and grade. Poult. Sci., 6(2):5161, 1926/27.

16. MeNALLY, E. H. \& SPICKNALL, N. H. - Meat yield from live, dressed and eviscerated Rhode Island Red chickens during growth and at maturity. Poult. Sci., 34(1):145-8, 1955.

17. McNALLY, E. H. \& SPICKNALL, N. H. - Meat yield from live, dressed and eviscerated Rhode Island Red males of broiler, fryer, and light roaster weights. Poult. Sci., 28(4):562-7, 1949.

18. MAY, K. N. \& BRUNSON, C. C. - Effect of lenght of starvation period on eviscerated yield of broilers apud Poult. Sci., 34(5):1210, 1955 .

19. MORAN, E. T. (jr.) \& ORR, H. L. Influence nf strain on the yield of commercial parts from the chicken broiler carcass. Poult. Sei., $49(3)$ : $725-9,1970$.

20. ORR, H. L. - Effect of strain, sex and diet on dressing percentage and on cooked meat yeld of 10 week old broilers. Poult. Sci., 34(5):1093-7, 1955.'
21. RAIMO, H. F. apud FONSECA, W.1 p. 63.

22. RANGANATHAN, M. et al. - A study on the dressing of Rhode Island Red,

White Leghorn and Desi cockerels. Indian vet. J., 44(11):956-61, 1967

23. REYNTENS, N. et al. - Essai comparatif de plusieurs races et croisements de poulets de chair: 2ème communication, La qualité de carcasse, Rev. agric. (Bruxelles), 13(1):35-55, 1960.

24. SANS EGANA, C. apud FONSECA, W.11 p. 58.

25. SARAZA, R. et al. - Nuevas aportaciones al estudio de la produccín del pollo broiler $y$ estudios complementarios sobre la canal y palatabilidad. Arch. Zootec. 9(35) :239-69, 1960.

26. SMIDT, M. J. et al. - Effect of fasting prior to slaughter on yield of broilers. Poult. Sci., 43(4):931-4, 1964.

27. SNEDECOR, G. W. \& COCHRAN, W. G. - Statistical methods. 6th ed. Ames, Iowa State University Press, 1967.

28. STOTTS, C. E. \& DARROW, M. I. Yields of edible meat from Cornish crossbreds, non-Cornish crossbreds, and purebred broilers. Poult. Sci., 32 (1) :145-50, 1953.

29. SWANSON, M. H. et al. - Factors affecting poultry meat yields. Stn Bull. Minn. agric. Exp. Stn., (476):1-36, 1964.

30. TADLE, J. et al. - Cooked, edible meat in parts of chicken. I. Broiler. $J$. Amer. diet. A88, 31 (6):597-600, 1955. Recebido para publicação em 18-8-75 Aprovado para publicação em 17-9-75 